Johan Frostegård Grant/research support from: Unconditional competitive grant from Amgen, related only to PCSK9, not the topic of this abstract DOI: 10.1136/annrheumdis-2020-eular.5547

\begin{tabular}{|l|l}
\hline AB0130 & SERUM ATHEROGENICITY IN WOMEN WITH \\
UNTREATED SYSTEMIC LUPUS ERYTHEMATOSUS
\end{tabular}

H. Gerasimova ${ }^{1}$, T. Popkova ${ }^{1}$, D. Gerasimova ${ }^{2}$, I. Sobenin ${ }^{3}$, A. Lila ${ }^{1} .{ }^{1}$ V.A. Nasonova Research Institute of Rheumatology, Moscow, Russian Federation; ${ }^{2}$ I.M. Sechenov First Moscow State Medical University (Sechenov University), Moscow, Russian Federation; ${ }^{3}$ National Medical Research Center of Cardiology, Moscow, Russian Federation

Background: Systemic lupus erythematosus (SLE) is associated with an unexplained increase cardiovascular risk. The nature of the factors that contribute to progression of atherosclerosis were identified using the method for determining the atherogenicity of blood serum in cell culture in cell culture (in vitro). The term "atherogenicity" is meant as the ability of the serum and/or its components to induce intracellular accumulation of cholesterol in cultured cells.

Objectives: To compare atherogenicity of blood serum in women with untreated SLE and healthy women.

Methods: Thirty seven women (median age 30[21;39] years) with active SLE (median disease duration 45[3;102] months; SLADAI 17 [8;34]) were enrolled in the study. Lupus nephritis are defined in 15 (41\%), Antiphospholipid syndrome (APS) - in $8(22 \%)$ of 37 SLE patients (pts). The control group consisted of 30 women, median age $31[25 ; 39]$ years.

Atherogenicity of blood serum was determined in the culture of murine macrophages. Peritoneal macrophages were isolated from the ascitic fluid of the line mice according to the generally accepted method J. Goldstein et al (1979y). Serum atherogenicity was determined by the accumulation of intracellular cholesterol induced by $10 \%$ of the blood serum of the patients, and expressed as a percentage of the content of cholesterol in the control cells.

Results: Elevated atherogenicity of blood serum was detected more frequently in SLE pts $(24 / 72(65 \%)$ vs healthy controls $(5 / 30(17 \%), p<0,01)$. The blood serum of SLE pts caused a 3-7-fold accumulation of intracellular cholesterol, which significantly differed from healthy women $(203 \pm 136 \%$ vs $127 \pm 42 \%, p<0,001)$. The ability to stimulate the accumulation of cholesterol esters in murine macrophages was not associated with age, duration of the disease, lipid spectrum and was the highest in pts with nephritis $(305 \pm 141 \%$ vs $180 \pm 52 \%, p<0,05)$ and APS $(253 \pm 130 \%$ vs $119 \pm 75 \%, p<0,05)$.

Conclusion: Serums of women with untreated SLE may stimulate the accumulation of cholesterol in mouse macrophages unlike of healthy women.

The highest atherogenicity was found in blood serum of SLE pts with nephritis and APS.

Disclosure of Interests: None declared

DOI: 10.1136/annrheumdis-2020-eular.5116

\section{AB0131 RESPIRATORY TRACT POLY(I:C) STIMULATION ACCELERATES SALIVARY GLAND IMMUNE DYSFUNCTION IN SPONTANEOUS SJOGREN'S SYNDROME ANIMAL MODEL}

P. Hu ${ }^{1}$, B. Ming ${ }^{1}, \mathrm{X} . \mathrm{Wu}^{1}$, L. Dong ${ }^{1}$ on behalf of NO. ${ }^{1}$ The Department of Rheumatology and Immunology, Tongji Hospital, Tongji Medical College, Huazhong University of Science and Technology, Wuhan, China

Background: Sjogren's syndrome is one of the most common autoimmune diseases, with a prevalence of $0.33 \%$ to $0.77 \%$ in Chinese people, characterized by focal infiltration of lymphocytes in glands and the production of multiple autoantibodies. Studies have shown that virus infection may play a crucial role in the occurrence and development of this disease.

Objectives: It has been shown that airway stimulation with poly(l:C) can mimic respiratory tract viral infection to some extent. Thus, this study was aimed to investigate the dynamic immune responses in salivary gland after respiratory tract poly $(I: C)$ stimulation in NOD mice.

Methods: The 5-week-old NOD mice were given respiratory tract poly $(\mathrm{l}: \mathrm{C})$ stimulation to mimic the respiratory virus infection once every other day for a total of 5 times (the total dose is $100 \mu \mathrm{g}$ ), and the control group were given the same dose of sterile PBS. After 8 weeks, the mice were sacrificed to obtain and analyze the salivary gland tissues.

Results: We found that the salivary gland flow rate was decreased and the blood glucose was influenced by the Viroid stimulation during the early stage in poly $(\mathrm{I}: \mathrm{C})$ stimulated group compared with that in PBS group. Accordingly, the pathological injury of salivary gland tissues in poly(I:C) stimulated group was more serious, including decreased volumes of the salivary glands, increased number of pathological focus score and the increased area of lymphocyte infiltration. Furthermore, we found that the expression of IL-33 in salivary glands of
poly(I:C) stimulated NOD mice was increased, especially the expression of IL-33 in the acini and ducts. Moreover, the expression of IFN-I and IFN-II is up-regulated in salivary glands.
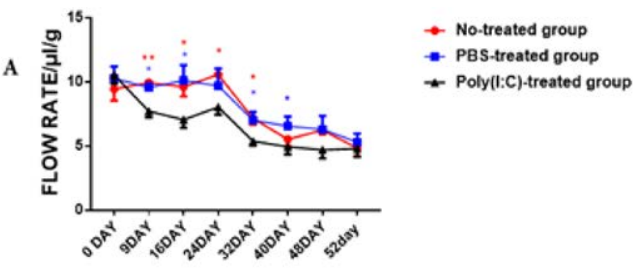

B

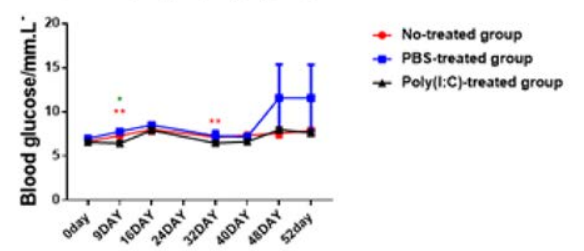

Figure1: Functional change of the NOD mice in different groups.

A. The dynamic change of the salivary gland flow rate; B. The dynamic change of the blood glucose

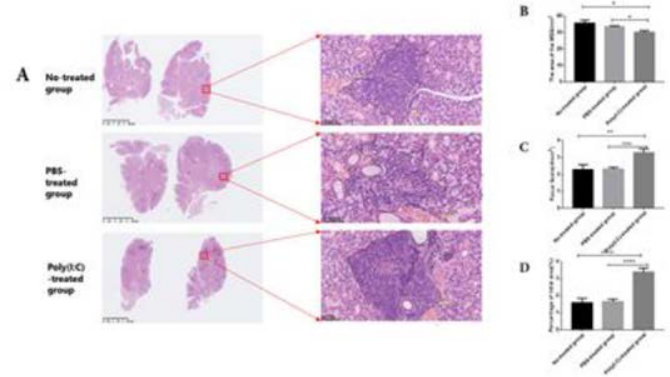

Figure2: Pathological changes of salivary glands in mice after different treatments A. The pathological changes of different groups; B. The quantitative analysis of the volume of salivary glands in different groups; $\mathrm{C}$. The quantitative analysis of the numbers of pathological lesions of salivary glands in different groups: D. The quantitative analysis of the areas of pathological lesions of salivary glands in different groups.
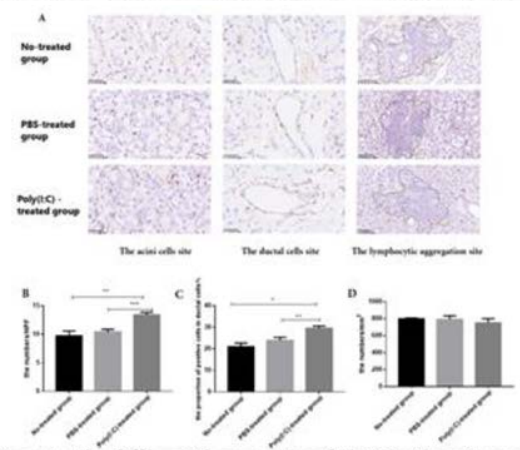

Figure3: The differential expression of IL-33 in the salivary glands. A. The expression of IL-33 in different sites of salivary glands; B. The quantitative analysis of the expression of IL-33 in the acini cells site; C. The quantitative analysis of the expression of IL-33 in the ductal cells site; D. The quantitative analysis of the expression of IL-33 in the lymphocytic aggregation site.

Conclusion: The results of this study suggest that respiratory tract poly(I:C) stimulation accelerates salivary gland immune dysfunction in spontaneous sjogren's syndrome NOD mice, which mechanisms need to be further investigated. References:

[1] Pathogenetic mechanisms in the initiation and perpetuation of Sjogren's syndrome. Nat Rev Rheumatol 2010; 6: 529-537.

[2] Primary Sjögren's Syndrome. N Engl J Med.2018 378(10):931-939.

[3] Epidemiology of primary Sjögren's syndrome: a systematic review and meta-analysis. Ann Rheum Dis 2015; 74: 1983-9.

[4] Vitamin D insufficiency in a large MCTD population. Autoimmun Rev 10:317-324.

[5] Epstein-Barr virus persistence and infection of autoreactive plasma cells in synovial lymphoid structures in rheumatoid arthritis. Ann Rheum Dis 72:1559-1568

[6] Liew, F., Girard, J. \& Turnquist, H. Interleukin-33 in health and disease. Nat Rev Immunol 16, 676-689 (2016) doi:10.1038/nri.2016.95

[7] Interleukin-33 and the function of innate lymphoid cells. Trends in Immunology, August 2012, Vol. 33, No. 8 
[8] Increased Levels of Interleukin 33 in Sera and Synovial Fluid from Patients with Active Rheumatoid Arthritis YASUSHI MATSUYAMA et al The Journal of Rheumatology January 2010, 37 (1) 18-25

[9] Potential involvement of the IL-33-ST2 axis in the pathogenesis of primary Sjogren's syndrome, Ann Rheum Dis, 2014, 73(6): 1259-1263.

[10] The Interleukin 33/ST2 axis in patients with primary Sjogren syndrome: expression in serum and salivary glands, and the clinical association, J Rheumatol, 2015, 42(2): 264-271.

[11] Kok MR, Baum BJ, Tak PP, et al Use of localised gene transfer to develop new treatment strategies for the salivary component of Sjögren's syndrome Annals of the Rheumatic Diseases 2003;62:1038-1046

Acknowledgments: NO

Disclosure of Interests: None declared

DOI: 10.1136/annrheumdis-2020-eular.3433

\section{AB0132 1 ALTERATIONS IN PERIPHERAL T-CELLS AND B-CELLS SUBSETS IN PATIENTS WITH SYSTEMIC LUPUS ERYTHEMATOSUS AND SJÖGREN'S SYNDROME UNDERGOING THERAPEUTIC PLASMA EXCHANGE OR IMMUNOADSORPTION}

Y. Jiang ${ }^{1}$, Q. Wei ${ }^{1}$, Q. Lv ${ }^{1}$, X. Zhang ${ }^{1}$, W. Zhu ${ }^{2}$, J. Gu ${ }^{1} .{ }^{1}$ The Third Affiliated Hospital of Sun Yat-Sen University, Rheumatology and Immunology, Guangzhou, China; 'ªazhou People's Hospital, Gaozhou, China

Background: Systemic lupus erythematosus (SLE) and Sjögren's syndrome (SS) are systemic autoimmune diseases characterized by a broad spectrum of clinical manifestations and disease course. Alternative therapies such as therapeutic plasma exchange (TPE), immunoadsorption are recommended to the patients who lack a good response to standard therapy [1].

Objectives: Our observational study was to explored whether abnormalities in T-cells, B-cells and their subtypes were present in the patients who had TPE or immunoadsorption in patients with SLE and SS compared with healthy controls $(\mathrm{HC})$.

Methods: Demographic, clinical variables and autoantibodies were recorded. Flow cytometry was used to establish the frequencies of lineage subsets. Monoclonal antibodies against 21 surface markers such as CD3, CD4, CD8, were used to distinguish and evaluate T-cells' and B-cells' subpopulation. SLE acvity was measured using systemic lupus erythematosus disease activity index (SLEDAI). Comparisons between subgroups were undertaken using paired T-test, Mann-Whitney $U$ test and ANOVA.
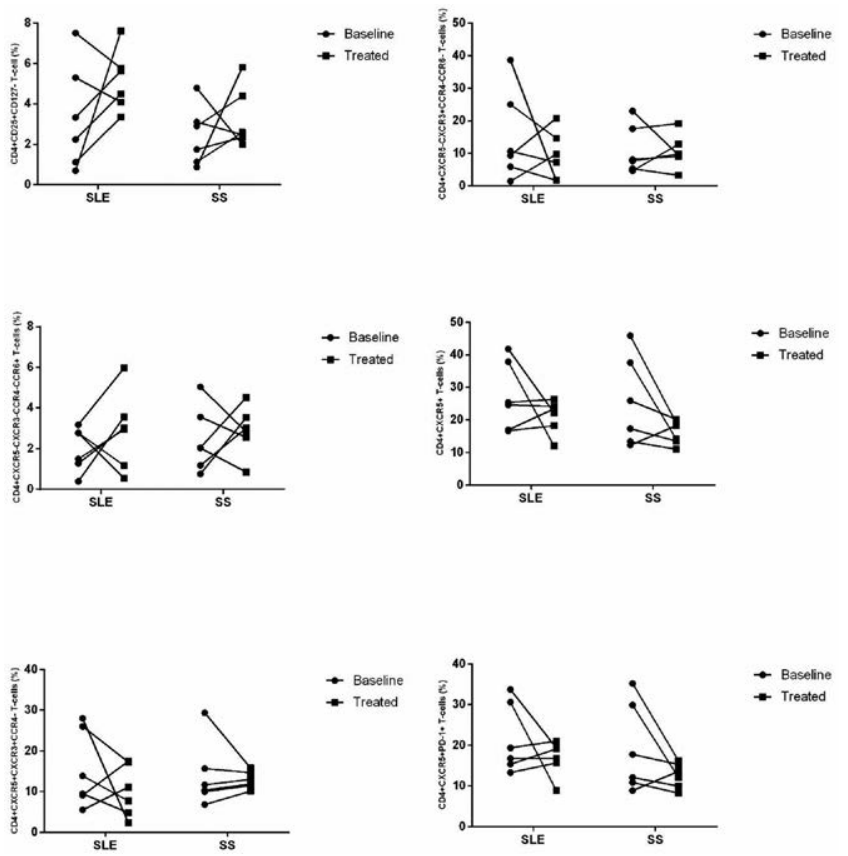

Figure 1. Altered expression of CD4+ T-cell subsets in the patients with SLE and SS after treated with plasma exchange or immunoadsorption

Results: 6 SS patients and 1 SLE patient underwent immune adsorption, while the other 5 SLE patients had plasma exchange all for three times. There was no significant difference among SLE, SS and HC in the proportion of T-cells and B-cells. The proportion of CD3-CD19+CD27+lgD+ B-cells were reduced in SLE, while CD3+CD4+CD25+CD127- T-cells were elevated in SS. The proportion of CD3+CD4+CD45RA+CCR7+T-cells were increased $(p=0.045)$, while CD3+CD4+CD25+CD127- T-cells were declined $(p=0.027)$ and CD3+CD4+CXCR5+PD-1+ T-cells went down after the therapies ( $p \leq$ $0.030)$. The proportion of CD3-CD19+lgD-IgM-CD27+CD38+ B-cells was also reduced after TPE or immunoadsorption $(p=0.032)$ with ANA titers and IgG decreasing dramatically. SLEDAI scores were reduced after the therapy in SLE patients.

Conclusion: The T-cell and B-cell's profiles were proved to have alteration after TPE or immunoadsorption which shed light on the complicated mechanisms of these relatively novel therapy in SLE and SS.

References:

[1] Bertsias GK, Tektonidou M, Amoura Z, et al. Joint European League Against Rheumatism and European Renal Association-European Dialysis and Transplant Association (EULAR/ERA-EDTA) recommendations for the management of adult and paediatric lupus nephritis. ANN RHEUM DIS 2012;71:1771-1782

Acknowledgments: None.

Disclosure of Interests: None declared

DOI: 10.1136/annrheumdis-2020-eular.725

\begin{tabular}{l|l}
\hline AB0133 & INCREASED SOLUBLE SEMAPHORIN 4D/CD100 IN \\
THE PLASMA OF SJÖGREN'S SYNDROME AND ITS \\
EFFECTS ON HUMAN SALIVARY GLAND CELL AND \\
CD4+ T CELL
\end{tabular}

S. E. Kang ${ }^{1}$, S. U. Kim ${ }^{1}$, R. H. Kim ${ }^{1}$, H. J. Yoo ${ }^{2}$, Y. J. Lee ${ }^{3}$, I. A. Choi ${ }^{4}$, J. K. Park ${ }^{2}$, E. Y. Lee ${ }^{2}$, Y. W. Song ${ }^{1,2}{ }^{1}$ Department of Molecular Medicine and Biopharmaceutical Sciences, Graduate School of Convergence Science and Technology, Seoul National University, Seoul, Korea, Rep. of (South Korea); ${ }^{2}$ Division of Rheumatology, Department of Internal Medicine, Seoul National University Hospital, Seoul, Korea, Rep. of (South Korea): ${ }^{3}$ Division of Rheumatology, Department of Internal Medicine, Seoul National University Bundang Hospital, Seoul, Korea, Rep. of (South Korea); ${ }^{4}$ Division of Rheumatology, Department of Internal Medicine, Chungbuk National University Hospital, Seoul, Korea, Rep. of (South Korea)

Background: Semaphorin 4D (SEMA4D) / CD100, known as a subfamily of axonal guidance proteins, has also been reported to act as an immunoregu lator in several infectious and inflammatory diseases [1]. Sjögren's syndrome (SS) is a systemic autoimmune disease that primarily affects the exocrine glands by infiltrated lymphocytes resulting in dryness of mouth and eyes. $\mathrm{IL}-17$ was reported to impair the integrity of tight junction barrier and attenuate the expression of aquaporin 5 (AQP5), causing salivary gland dysfunction in SS [2].

Objectives: This study was aimed to evaluate the role of SEMA4D in patients with SS and investigate the effect of SEMA4D on human salivary gland epithelial cell (SGEC) and T cell.

Methods: Soluble SEMA4D levels in plasma were measured by enzymelinked immunosorbent assay (ELISA) from patients with SS, non-SS sicca and healthy controls. Immortalized human SGECs, originated from acini (NS-SV-AC) and duct (NS-SV-DC), were used to evaluate the effects of SEMA4D. CD4 ${ }^{+} \mathrm{T}$ cells from human peripheral blood were isolated to determine the secretion of cytokines in response to SEMA4D. IFN- $\gamma$ and IL-17 were used to determine the effects on AQP5 expression of SGEC.

Results: The levels of soluble SEMA4D in plasma were increased in patients with SS (median [interquartile range]: 1221.3 [393.5] pg/mL) com pared to non-SS sicca $(940.2[355.1] \mathrm{pg} / \mathrm{mL}, p=0.006)$ or healthy controls (909.5 [108.0] pg/mL, $p<0.0001)$. The levels of soluble SEMA4D in plasma were correlated with the levels of several autoantibodies including anti-SSA (Spearman's rho $=0.358, p=0.006$ ), anti-SSB (rho $=0.350, p=0.007$ ), and anti-muscarinic receptor 3 (M3R) Ab (rho $=0.495, p<0.001$ ), and also correlated with total IgG ( $r$ o $=0.431, p=0.002$ ). SEMA4D-stimulated SGECs showed decreased expression of tight junctions such as occludin and Zo-1. $\mathrm{CD}^{+} \mathrm{T}$ cells secreted IFN- $\gamma(p=0.025)$, IL-17 $(p=0.028)$, and IL-21 ( $p=$ 0.007 ) with SEMA4D stimulation. IFN- $\gamma$ and IL-17 decreased AQP5 expression in SGECS.

Conclusion: SEMA4D contributed to decreased expression of tight junction in SGECs. SEMA4D induced production of IFN- $\gamma$ and IL-17 in $\mathrm{CD}^{+}{ }^{+} \mathrm{T}$ cells and these cytokine decreased AQP5 expression in SGECs.

References:

[1] Worzfeld T, Offermanns S. Nat Rev Drug Discov. 2014;13(8):603-21.

[2] Bhattarai KR, Junjappa R, Handigund M, Kim HR, Chae HJ. Autoimmun Rev. 2018;17(4):376-90.

Disclosure of Interests: None declared

DOI: 10.1136/annrheumdis-2020-eular.5162 